\title{
Schäffner, Christina and Bassnett, Susan (eds). 2010. Political Discourse, Media and Translation. Newcastle upon Tyne: Cambridge Scholars Publishing.
}

\author{
Cecilia Foglia \\ University of Montreal, Canada
}

Are we well informed? This is the (provocative) question that one might raise after reading this volume, a collection of articles tackling the notion of recontextualization in news translation, with a special focus on political discourse. The book, which provides some answers to the intricate relationship between translation and media, investigates the complex (and most often invisible) work of news translators. Journalists, as well as media in general, play the crucial role of mediators between institutions, their representatives and the public. Our knowledge of governmental activities, political communications, public addresses, etc., entirely depends on media. When translating some news in order to report from foreign countries, journalists filter, select, add, omit and adapt information, which contributes to releasing some localized news version for the new target audience. In brief, they recontextualize it. But, one might wonder, are they really conscious of their power, their agency, the consequences, effects and impact that such manipulations of the information can have on the public?

Although, on the one hand, journalists tailor the way we come to grips with a culture, hardly ever are they trained as translators, and as a consequence, they perform their task without bearing in mind some of the traditional concerns of Translation Studies (TS). One such concern is the issue of fidelity between source and target texts. Who, then, dictates the rules of the(ir) game? One could argue that newspapers and TV political orientations, as well as advertising investors' economic interests - to name a few-do indeed influence news translation. However, they are just the tip of the iceberg of a (much wider) manipulative process.

The reasons for such transformations, and the way recontextualization and/or localization are carried out, perhaps, are more intricate than it might initially seem, and may be grounded in arbitrary decisions: namely, decisions made by those who select the information to be translated from the very start on the basis of specific, yet subjective, strategies. But, what are these strategies or techniques? Who revises the 'final product'? How does reception influence decision-making? Why are articles seldom labeled as translations? Why do journalists rarely define themselves as translators?

Political Discourse, Media and Translation is the printed outcome of a symposium held in February 2007 at Aston University. The collected papers shed light on the above questions in a somewhat provocative fashion intellectually speaking. Their overall goal is not to cast doubt on or assess the profession of journalists as translators, but to demonstrate that the principle of equivalence applied to news translation does not serve 
the journalists' agenda, and that we had better examine this sub-field in a more interdisciplinary way. The editors Christina Schäffner and Susan Bassnett point out in the overture, that this is made possible by the two-fold purpose of the book. First, it aims at investigating the role played by translation and its agents in international political communication and news reporting. Secondly, it seeks to explore the invisible and mostly uncharted link between politics, institutions, media and translation. In this sense, the present volume aspires to bridge this epistemological gap within TS. The book is divided into two parts of five chapters each. The first part, preceded by an introduction signed by the editors, covers the first above-mentioned purpose. It focuses on textual analysis in order to pragmatically display the transformations that occur while translating news. The second part, followed by a postscript signed by Yves Gambier, is devoted to the achievement of the second objective, and digs into institutional contexts and policies to gauge their impact on translation production and reception. All contributors have examined news translation from the TS perspective.

In the introduction, Schäffner and Bassnett explore the synergy between politics, media and translation. The common thread underlying them is the power of language. Politics is essentially conducted through language, thus echoing Paul Chilton's (1997) statement that even a declaration of war is primarily a linguistic act. Media, the so-called 'fourth estate', report on politics at incredible speed through language (and technological devices) and consequently translation. In a nutshell, in disseminating political information, media select, filter, summarize, etc., the content of political communication, thus transforming and recontextualizing the original message for the new target audience. Obviously, this manipulation both influences the reactions of the public and the speech strategies of politicians. The editors point out that if, on the one hand, the public remains unaware of these translating processes, because journalists conceal the translating activity behind news reporting, on the other hand, the concept of the translator as an invisible conveyor of meanings has been substituted by that of a visible interventionist. Therefore, Schäffner and Bassnett suggest that scholars should prioritize the study of journalists/translators' agency, the relation between socio-cultural aspects and translation, and its effects on readers. Textual analysis based on the detection of linguist shifts proves to be less informative and challenging than the adoption of an intercultural and interdisciplinary approach to news translation. Lastly, is the label 'translation' really applicable to news translation? After all, it escapes traditional models of interlingual translation "and comes closer to what happens in interpreting, where the goal of the transaction is more important than any sense of equivalence" (9). In the wake of this careful consideration, Schäffner and Bassnett leave the floor to the contributors.

Siobhan Brownlie investigates the way British newspapers have reported the 2007 French presidential election campaign. Inspired by Pierre Bourdieu's sociology of structured and structuring field, the author aims at demonstrating that language use varies according to the 'positioning' in which a newspaper report is embedded. She therefore develops an analytical framework where she lists the potential elements that influence and determine recontextualization. Thus, the language use can change according to the positioning of the newspaper, the genre, the journalist and the 
addressee; the intercultural and the transcultural positionings, and finally, the sociohistorical positioning of the target culture. By providing concrete examples, she proves that news translation is the result of interlingual and intercultural operations, and that journalists' status (or positioning) within newsrooms is directly proportional to the freedom they are granted when recontextualizing news. As a consequence, shifts in perspective may occur among readers.

In the same vein, Elpida Loupaki brings to the fore a different case study to investigate recontextualization and the impact ideology has in news translation. She examines the strategies and the techniques used by journalists to translate news displaying ideological conflict embedded in the source text (ST). Moreover, she also attempts to investigate the factors that influence journalists/translators' choices. The term 'conflict' is not to be considered here in the sense of fighting. It indicates the influence that certain factors like emotive words, modals, euphemisms, etc., embedded in the ST, may have on journalists, whose interpretation can thus become biased. By analyzing the way two Greek newspapers have translated articles from the AngloAmerican press, she detects the three main strategies used to reproduce an ideological conflict: literary translation (to reproduce the same ideological conflict), neutralization and omission (to erase it), and addition or explicitation (to introduce a new conflict). She also questions whether it would be more appropriate to coin a new term, like 'transjournalist', to refer to news translators.

In the wake of Loupaki, Cristina Caimotto proposes the term 'trans-reporting' to refer to the journalists' translating activity. She examines how Wolfgang Munchau's article on the Italian economic situation after elections (2006) has been translated by three different Italian newspapers. The results of her inquiry show that journalists never label their article as a translation, and that a manipulation of the ST has occurred. In fact, instead of prioritizing the Italian economic situation, journalists emphasize the personal face-off between Romano Prodi and Silvio Berlusconi, the two candidates running for the post of Prime Minister (PM). Caimotto argues that this biased recontextualization is due to linguistic and socio-cultural reasons. By omitting crucial sentences, adding personal judgments and playing with the punctuation and the position of adjectives, journalists guide and shift readers' opinions. Still, Italian journalists aim to satisfy their readers' expectations. In fact, the latter definitely prefer devouring articles where sensationalism and infotainment exceed precision. The author concludes that time pressure, journalists' sloppiness and lack of professional training in translation may represent the main ingredients for altered reports.

Ewa Gumul advocates the use of the term 'press translation' with reference to reporting news. Starting from a wide corpus of articles published by Anglo-American newspapers between 2003 and 2007, and translated into Polish, she aims at exploring the manipulative potential of explicitation to determine the extent to which journalists/translators' interventions contribute to altering the point of view developed by the target text (TT). She provides an exhaustive and useful chart of possible types of explicitation. Afterwards, she adjusts Hatim and Mason's (1997) model of three degrees 
of translators' mediation in order to facilitate quantitative analysis. The level of mediation will be minimal, partial or maximal depending on the number of (ideological) shifts embedded in the T'T. She concludes by arguing that explicitations in political translations alter the reader's standpoint. However, her investigation allows a quantitative but not qualitative study of journalists/translators' propensity for explicitation. Thus, an in-depth inquiry on their intentionality could open a new avenue for exploration in TS.

Federico Federici concludes the first part of the volume by choosing a burning issue for the American versus the Italian foreign policies: the Calipari Case. Nicola Calipari was an Italian security agent who was accidentally killed by American soldiers in Baghdad, in 2005. The author comments on two aspects of this case and its translations: legitimization of the US report as a ST, and legitimizations of its translations. By using two different approaches, like the Critical Discourse Analysis (CDA) and the Systemic Functional Linguistics, he demonstrates that Italian journalists/translators have largely selected, omitted passages and added personal comments to the TT in order to ideologically manipulate and legitimize the text. As Federici explains, legitimizing a text means "imposing one perspective as a universal truth, through the manipulation of persuasive components of the sentence" (118). With reference to TS, legitimization means "positive self-representation and negative presentation of the others, [...], by using specific translation strategies, [...] or abusing texts for purposes of national ideologies" (Schäffner: 2004, 145, cited by Federici, 118). Whereas the US report tries to legitimize one single perspective of the event (obviously oriented to stress the accidental nature of the shooting), Italian media have much speculated on the fact and provided several versions of that. Federici's conclusions seem to confirm Caimotto's theory of Italian journalism being more inclined to infotainment and sensationalism than to content rigor. After all, this makes bad news more attractive or digestible.

Moving from textual, empirical analysis to context analysis, Ubaldo Stecconi inaugurates the second part of the volume. He brings to light the European Union (EU) politics, which is one of multiculturalism. This means that the EU does not only provide translations into each language of its Member States, but also praise for diversity. Hence, the implementation of a multicultural policy comprises the promotion of all cultures, and not exclusively of languages. Differently from the USA, the purpose of the European institution - as Stecconi claims - is not to impose a melting, but a melding pot. Thus, translating in all languages epitomizes the way to promote diversity and avoid any intercultural conflict; offer a significant alternative to the unilingualism caused by globalization; promote language learning; guarantee excellent communication, and, finally, overcome linguistic barriers impeding the circulation of capital.

Luc van Doorslaer, on the contrary, seems to debate this idea of translation as a bridge between institutions, media and the public, especially in a country like Belgium. Its intricate bi- or multilingual context affects the way in which political discourse is presented and translated for the public. The author shows that compromises between the two main language communities (the French and the Dutch ones) can be reached through well-balanced formulations able to undermine ideological and nationalistic 
tensions. However, as he demonstrates through the example of the expression "faciliteitengemeeenten" / "communes à facilite"” (municipalities with linguistic facilities), when the peacekeeping power of translation is too emphasized, it risks becoming excessively cryptic, thus leaving room for misinterpretation.

Chantal Gagnon explores the role of the institutional context in the production and the translation process of political speeches and addresses delivered in English and French by Canadian Prime Ministers (PMs). Reception is not taken into account for this inquiry. She focuses on four PMs belonging to different historical moments, from 1921 to 2003. Her investigation aims at answering three different questions: Who translates PMs' speeches? Does the translation process differ from one historical period to another? Do text types have repercussions on the translation process of Canadian political communications? The results of her research show that the translation process/production changes in time, and that the process may vary within one PM's mandate. She also proves that after the $20^{\text {th }}$ century, different text types were translated by different categories of translators. For instance, most parliamentary speeches were translated overnight by professional translators, while PMs' speeches delivered via television were translated by political aids. She also gives evidence of a certain mistrust towards professional translators, "especially when it comes to mediating the PMs' image in the 'spoken' media" (173). Gagnon enriches her research by describing translators' hardworking conditions within the institution and by debating the notion of ST in political contexts.

In the same vein, Claire Tsai questions the definition of ST versus TT and reflects on both differences and similarities between translators and journalists. She aims at studying the TV news translator as a profession, and for this reason, she conducts interviews with her former colleagues working for the newsroom of Taiwan's Formosa Television (FTV). Tsai's research shows that FTV's news production heavily relies on scripts made available by international agencies. Differently from other media, which could consider these scripts as the final version of some news ready to be delivered via television, FTV news translators treat them like some raw material to re-elaborate. Thus, they consult other sources (like agencies, YouTube, online material, etc.) to construct a new final version upgraded with translators' comments, expectations and opinions. This craftsmanship, which much resembles the collage art, is absolutely target oriented and transforms the news translator into a multitask commentator working with multisource texts. His TT, produced at a very high speed, has little to do with the ST and offers new angles of the same news. Eventually, Tsai suggests studying news translation within the field of Media Studies and not TS, and considering news translators as reporters, because of their high degree of authorship of the T'T. In fact, they feel all but subservient to the ST.

Stuart Price explores the dissemination of the political discourse and its mediation in Greece, starting from the evolution of the concept of democracy. In the democratic Athenan polis (state), which flourished in the period 462 to $322 \mathrm{BCE}$, the term 'democracy' designated a state actively and directly governed by its citizens. Therefore, 
they did not delegate their authority to any elected representatives. Thus, mediation was not needed. Nowadays, we are witnessing a shift in the meaning of the concept. Democracy no longer refers to the citizens' engagement in politics, but to their right of political transparency from those who have been voted to represent them. Through this insightful historical elucidation, Price explains why media were born: that is to compensate for citizens' indirect exercise of power, or rather, passivity. Afterwards, he illustrates how the Greek Ministry of Foreign Affairs uses the Internet as a tool for political communication. However, Price wonders if websites are really meant for national and international adequate information on Greek politics. He rather doubts that the adoption of technological devices actually serves the democratic cause (in its modern meaning) of political transparency. After all, the informative level of these multilingual webpages is quite poor and generic, and users' access to blogs where they can leave comments, chatrooms, etc., is just a public façade and not a real means of extending democratic engagement.

Yves Gambier's contribution serves as a postscript to the volume and offers a farreaching reflection on the invisible link between media, politics and translation. He calls for more empirical studies into the role played by translation for public communications, and suggests going beyond linguistic analysis to explore, in more details, the socioeconomic context where translation takes place. Gambier sets a good example by exploring public communication from three different angles: beyond national boundaries, beyond media boundaries, and beyond the discipline boundaries. Through a sort of maieutic technique based on numerous questions raised, he comes to the conclusion that information and communication technology are inseparable, and most importantly, that "individual voices (that is common people) are changing the public discourse" (236). He also argues that TS has built bridges with other disciplines like sociology, media studies and international relations, even though two other directions can be taken into account: the audience study (that is reception) and the research in visual aspects of international news. In short, the time has come for TS to go beyond its traditional boundaries.

Political Discourse, Media and Translation is an outstanding tribute to the interdisciplinary nature of TS. Page after page, it discloses the crucial role that the translator's agency plays within this discipline and in relation to the public. The translator's invisibility is undoubtedly replaced by her/his interventionism, and this opens the way for further questions such as the ethics of translation, the impact of both recontextualization and manipulation on the target audience. However, if on the one hand, this volume offers through text analysis a comprehensive description of the process of news translation by media, on the other hand, it is less exhaustive when discussing translation within and for institutions. Moreover, apart from Tsai's contribution focusing on Taiwan's Formosa Television, the rest of the volume discusses news translation in a western context and from a western point of view. It would have perhaps been interesting to see how public communications are translated and mediated in non-western institutions and societies. Nonetheless, the clarity, the precision and the accuracy of the content, as well as the interdisciplinary character of the whole book, make of this contribution a benchmark for 
scholars and students involved in the fields of TS, sociology, psychology, international relations, cultural and media studies.

In conclusion, Political Discourse, Media and Translation is a pragmatic example of the exploration of the openness of the definition of news translation "and the implications of that openness for the emerging international discipline [translation]" (Tymoczko, 2007: 58). 


\section{REFERENCES}

Chilton, Paul. 1997. The Role of Language in Human Conflict: Prolegomena to the Investigation of Language as a Factor in Conflict Causation and Resolution. Current Issues in Language \& Society 4(3): 174-89.

Schäffner, Christina. 2004. Critical Discourse Analysis from the Point of View of Translation Studies. Journal of Language and Politics 3.1:117-50.

Tymoczko, Maria. 2007. Enlarging Translation, Empowering Translators. Manchester, UK\&Kinderhook (NY), USA: St Jerome Publishing. 